\title{
Familial Renal Cancer: Molecular Genetics and Surgical Management
}

\author{
Glen W. Barrisford, ${ }^{1}$ Eric A. Singer, ${ }^{2}$ Inger L. Rosner, ${ }^{1}$ \\ W. Marston Linehan, ${ }^{2}$ and Gennady Bratslavsky ${ }^{2,3}$ \\ ${ }^{1}$ Department of Urology, National Naval Medical Center, Bethesda, MD 20889, USA \\ ${ }^{2}$ Urologic Oncology Branch, Center for Cancer Research, National Cancer Institute, National Institutes of Health, \\ 10 Center Drive, Building 10, Room 1-5940, Bethesda, MD 20892, USA \\ ${ }^{3}$ Department of Urology, Upstate Medical University, SUNY, Syracuse, NY 13210, USA
}

Correspondence should be addressed to Gennady Bratslavsky, bratslag@upstate.edu

Received 1 March 2011; Accepted 31 May 2011

Academic Editor: Bernardo Garicochea

Copyright ( $\odot 2011$ Glen W. Barrisford et al. This is an open access article distributed under the Creative Commons Attribution License, which permits unrestricted use, distribution, and reproduction in any medium, provided the original work is properly cited.

Familial renal cancer (FRC) is a heterogeneous disorder comprised of a variety of subtypes. Each subtype is known to have unique histologic features, genetic alterations, and response to therapy. Through the study of families affected by hereditary forms of kidney cancer, insights into the genetic basis of this disease have been identified. This has resulted in the elucidation of a number of kidney cancer gene pathways. Study of these pathways has led to the development of novel targeted molecular treatments for patients affected by systemic disease. As a result, the treatments for families affected by von Hippel-Lindau (VHL), hereditary papillary renal carcinoma (HPRC), hereditary leiomyomatosis renal cell carcinoma (HLRCC), and Birt-Hogg-Dubé (BHD) are rapidly changing. We review the genetics and contemporary surgical management of familial forms of kidney cancer.

\section{Introduction}

Renal cell carcinoma (RCC) has a global impact with approximately 111,100 new cases and 43,000 deaths from the disease among men in developed countries in 2008 alone [1]. In 2010, RCC ranked as the seventh and eighth most common malignancy in men and women in the United States, respectively, and 58,240 new cases and 13,040 deaths were expected [2]. Americans face a diagnosis of renal malignancy at a rate of approximately 1 in 67 over the course of their lifetime [3]. The increased availability and use of cross-sectional imaging as well as other imaging modalities tends to diagnose renal tumors at earlier stages and often as incidental findings. However, despite the increased and advanced detection, the associated mortality rate has not declined [4]. Unexpectedly, the increased incidence of RCC cannot be entirely explained by the more widespread use of imaging modalities [5].

Surgical resection has historically been the mainstay of therapy as RCC is known to be resistant to radiation and traditional chemotherapy $[6,7]$. Although surgical resection is often curative, up to $30 \%$ of patients will present with systemic disease, while an additional 30\% will develop metastatic lesions in followup after an initial presentation of organ confined disease [8]. Treatment of systemic disease has often been challenging due to the fact that RCC represents a heterogeneous spectrum of diverse entities. Each subtype of renal malignancy is known to possess unique clinical characteristics, genetic alterations, and has varied responses to therapy. The dominant malignant subtypes recognized by the Heidelberg classification system include clear cell (conventional) (70-80\%), papillary (chromophile) (10-15\%), chromophobe (3-5\%), and collecting duct (1\%) tumors [9]. Papillary tumors are further stratified into type $1(5 \%)$ and type $2(10 \%)$ based upon genetic and histologic variation [10-12] (Figure 1).

RCC can exist as both hereditary and sporadic entities. Sporadic RCC typically presents as a solitary lesion and will occur more commonly in patients in the sixth decade and beyond. Conversely, hereditary forms of kidney cancer often present with multifocal, bilateral tumors and may present 


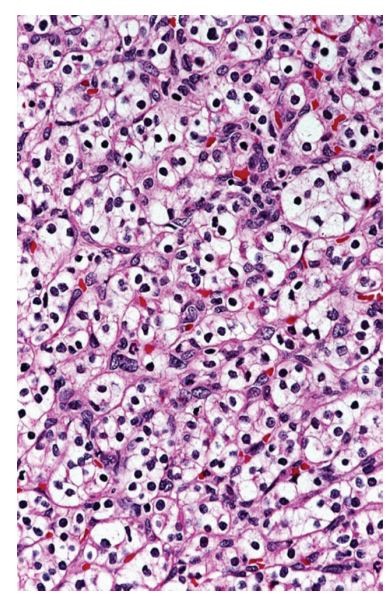

(a)

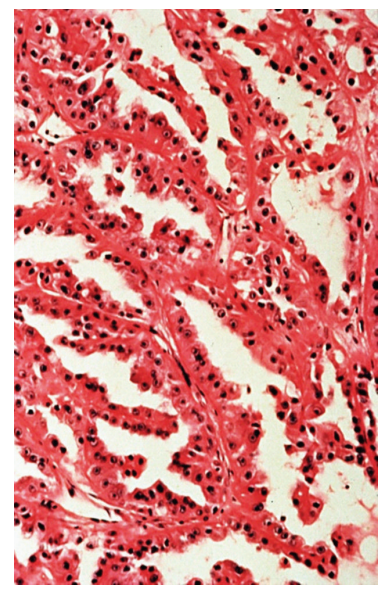

(c)

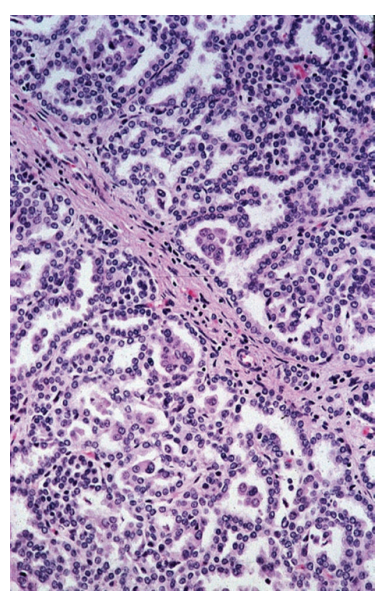

(b)

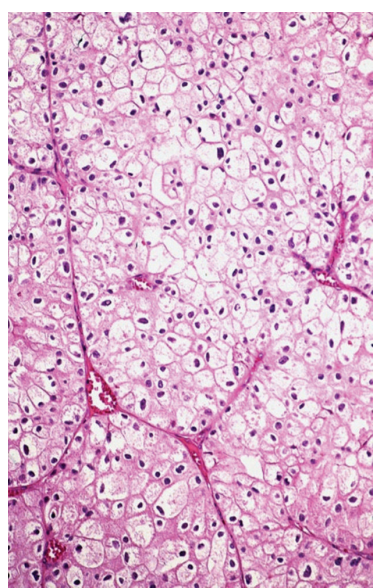

(d)

Figure 1: Histopathology of the most common malignant renal neoplasms. (a) Clear cell; (b) papillary type 1; (c) papillary type 2; and (d) chromophobe. (From Linehan et al. [10], with permission.)

in far younger patients [13]. Many cases of hereditary renal malignancy go unrecognized or unreported as this spectrum of diseases is not well understood [14]. Moderate estimates place hereditary disease forms at $3-5 \%$ of the overall number of diagnoses $[15,16]$. Liberally defined, familial renal cancer (FRC) is noted to exist when more than one member of a family presents with a single malignancy or collection of tumors [16].

The identification of FRC is critical in that it allows for the early screening of families, vigilant followup for those affected, appropriate and measured interventions when needed, and the reduction of disease-related morbidity and mortality. When a patient's family history is positive for kidney cancer, or a patient with one or more of the physical/radiographic findings outlined in Table 1 is found to have a renal mass, further investigation and referral to a genetic counselor are often reasonable. The American Society of Clinical Oncology's recently published guidelines on genetic testing for cancer susceptibility concisely identify and explain many of the ethical issues associated with germ line analysis [17].

FRC is a heterogeneous disease comprised of a spectrum of varied histologic subtypes. The fundamental link among the forms of FRC with a known genetic alteration is that they are metabolic in nature, as the genes involved with FRC are associated with abnormalities in oxygen, iron, glucose, and energy sensing [18]. The identification of genetic aberrations associated with familial forms of kidney cancer has led to the elucidation of a number of interrelated metabolic pathways. As a result, a number of targeted molecular therapies have developed over the past half decade [19]. This has altered the management of advanced and systemic RCC and provided additional approaches to cytokine-based therapies for the systemic therapy of clear cell tumors [20,21]. The treatment of choice for nonclear cell histologies is presently less well defined [22]. Understanding the genetic abnormalities and the pathways leading to the tumorigenesis of FRC provided the opportunity for the development of novel forms of therapies targeting these cancer gene pathways (Table 1).

\section{Von Hippel-Lindau}

Von Hippel-Lindau (VHL) is a hereditary renal cancer syndrome associated with clear cell renal tumors. The inheritance pattern is autosomal dominant, and the incidence is 1 in 36,000 live births $[10,24,25]$. The disease can manifest 
TABle 1: Familial renal cancer syndromes.

\begin{tabular}{|c|c|c|c|c|c|}
\hline Syndrome & Phenotype & Renal cancer manifestation & Gene & Chromosome & $\begin{array}{c}\text { Mendelian } \\
\text { Inheritance in Man } \\
\text { (MIM) number }\end{array}$ \\
\hline $\begin{array}{l}\text { Von } \\
\text { Hippel-Lindau } \\
\text { (VHL) }\end{array}$ & $\begin{array}{l}\text { Renal tumors, adrenal } \\
\text { pheochromocytomas, retinal } \\
\text { angiomas, central nervous } \\
\text { system hemangioblastomas, } \\
\text { pancreatic cysts and } \\
\text { neuroendocrine tumors, } \\
\text { endolymphatic sac tumors, } \\
\text { epididymal and broad ligament } \\
\text { cystadenomas }\end{array}$ & Clear cell renal cell carcinoma & $V H L$ & $3 p 25$ & 193300 \\
\hline $\begin{array}{l}\text { Hereditary } \\
\text { papillary renal } \\
\text { carcinoma (HPRC) } \\
\end{array}$ & Bilateral, multifocal renal tumors & $\begin{array}{l}\text { Papillary renal cell carcinoma } \\
\text { type } 1\end{array}$ & $M E T$ & $7 q 31$ & 164860 \\
\hline $\begin{array}{l}\text { Hereditary } \\
\text { leiomyomatosis } \\
\text { and renal cell } \\
\text { carcinoma } \\
\text { (HLRCC) }\end{array}$ & $\begin{array}{l}\text { Skin and uterine leiomyomas, } \\
\text { renal tumors }\end{array}$ & $\begin{array}{l}\text { Papillary renal cell carcinoma } \\
\text { type } 2\end{array}$ & $\mathrm{FH}$ & $1 q 42-43$ & 605839 \\
\hline $\begin{array}{l}\text { Birt-Hogg-Dubé } \\
\text { (BHD) }\end{array}$ & $\begin{array}{l}\text { Cutaneous fibrofolliculomas, } \\
\text { lung cysts, spontaneous } \\
\text { pneumothorax, renal tumors }\end{array}$ & $\begin{array}{l}\text { Hybrid oncocytic, } \\
\text { chromophobe, and clear cell } \\
\text { renal cell carcinoma; } \\
\text { oncocytoma }\end{array}$ & FLCN & $17 \mathrm{p} 11$ & 135150 \\
\hline
\end{tabular}

clinically with renal tumors, adrenal pheochromocytomas, retinal angiomas, central nervous system hemangioblastomas, pancreatic cysts, neuroendocrine tumors, endolymphatic sac tumors, and cystadenomas of the epididymis and broad ligament. Each of these tumors is known to be highly vascular. Improvement in treatment for central nervous system tumors has had the effect of elevating metastatic renal cell carcinoma to the leading cause of mortality among these patients. Renal tumors appear in $35-45 \%$ of affected individuals, can be solid or cystic, and are of clear cell histology [26]. Patients can develop up to 600 microscopic tumors and over 1100 cysts per kidney [13, 24].

VHL-associated tumors were noted to have a consistent loss of the short arm of chromosome 3 [27]. Genetic linkage studies in patients with hereditary and sporadic renal cancer led to the identification of the VHL gene on the short arm of chromosome $3(3 \mathrm{p} 26-25)[28,29]$. This gene is a tumor suppressor, and the loss of a single normal allele was observed in the VHL gene in kidney cancer tissue samples [30]. This observation suggested that there existed an inherited gene at this location. This germline alteration was observed in VHLassociated kidney cancer and is found in nearly $100 \%$ of VHL families [31]. Somatic VHL alterations are observed in a high percentage of sporadic clear cell renal tumors but are absent in papillary, chromophobe, or collecting duct tumors [32]. There are currently more than 300 known alterations available for testing that involve the VHL gene $[33,34]$. The location and type of the VHL gene alteration can result in the expression of different phenotypes. Penetrance is widely varied, and certain traits (pheochromocytomas) tend to be clustered in certain families while absent in others [35]. Patients with partial germline deletions are noted to have a higher incidence of RCC and greater extent of involvement among various organ systems as compared to those with complete deletions [33, 36, 37].

VHL gene function has been rigorously studied. It is a relatively small gene encoding 854 nucleotides on three exons and encodes the VHL protein [29]. The VHL protein (pVHL) forms a complex with elongin $\mathrm{B}$, elongin $\mathrm{C}, \mathrm{Cul} 2$, and Rbx1 [38-40]. This complex targets the hypoxia-inducible factors (HIF), HIF- $1 \alpha$ and HIF- $2 \alpha$, and is essential for ubiquitinmediated degradation $[41,42]$. The transcription products of HIF- $1 \alpha$ and HIF- $2 \alpha$ are known to regulate a number of downstream genes that are involved in tumorigenesis. The main examples of these genes are vascular endothelial growth factor (VEGF), platelet derived growth factor (PDGF), epidermal growth factor receptor (EGFR), transforming growth factor (TGF- $\alpha$ ), and glucose transporter (GLUT-1). During conditions of normal tissue oxygen levels, the VHL complex binds to HIF initiating ubiquitin-mediated degradation. However, during conditions of low tissue oxygen levels, the VHL complex does not degrade HIF which results in a surge of HIF levels and an upregulation of transcription of HIF-dependent genes [13, 43]. In the instance of clear cell RCC, a VHL gene alteration changes the alpha domain (which binds elongin $\mathrm{C} / \mathrm{B}$ and $\mathrm{Cul} 2$ ) or the beta subunit (which targets HIF for breakdown). These changes result in a buildup of HIF and consequently an increased expression of the downstream genes (Figure 2). The pVHL protein causes an effect similar to hypoxia and can activate pathways for cellular proliferation and neovascularization. This effect takes place under normoxic conditions and has been termed "pseudohypoxia" [12, 44]. Many of the current therapeutic management approaches for clear cell 


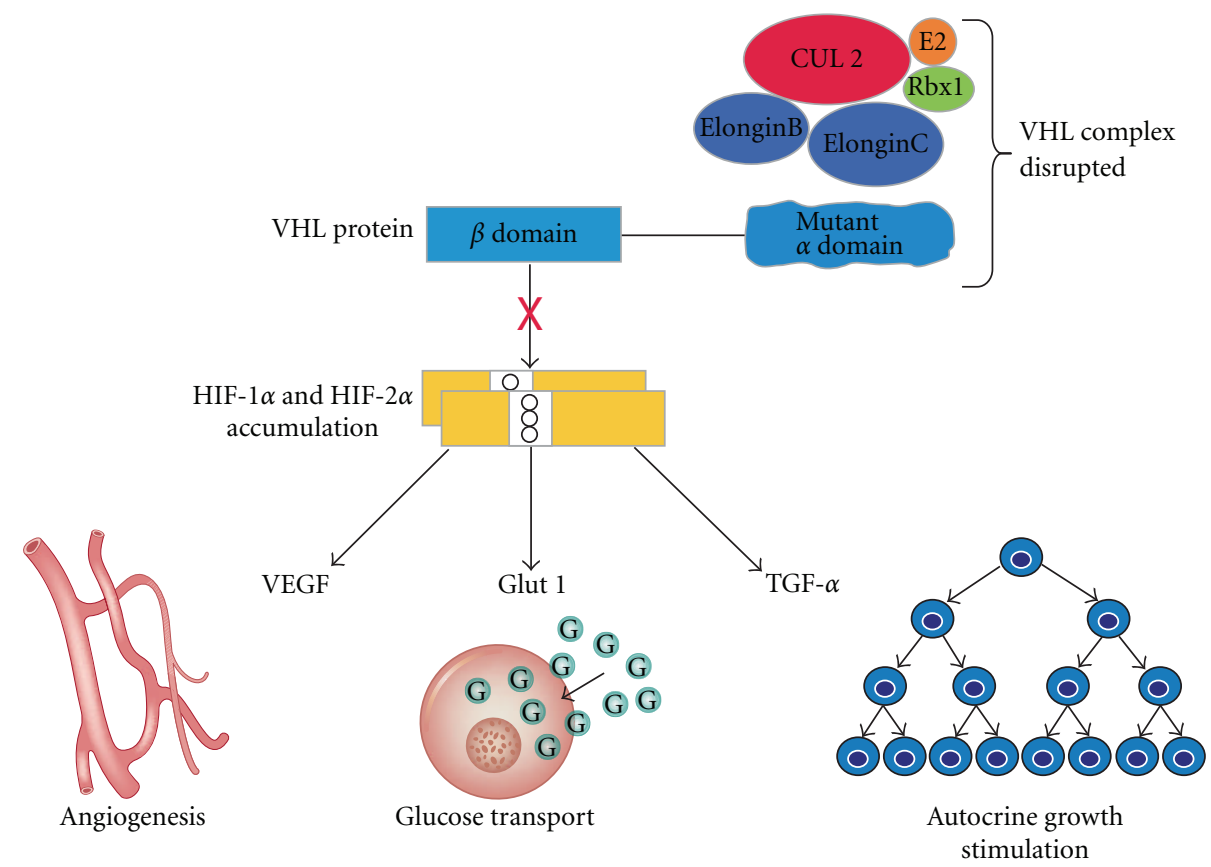

(a)

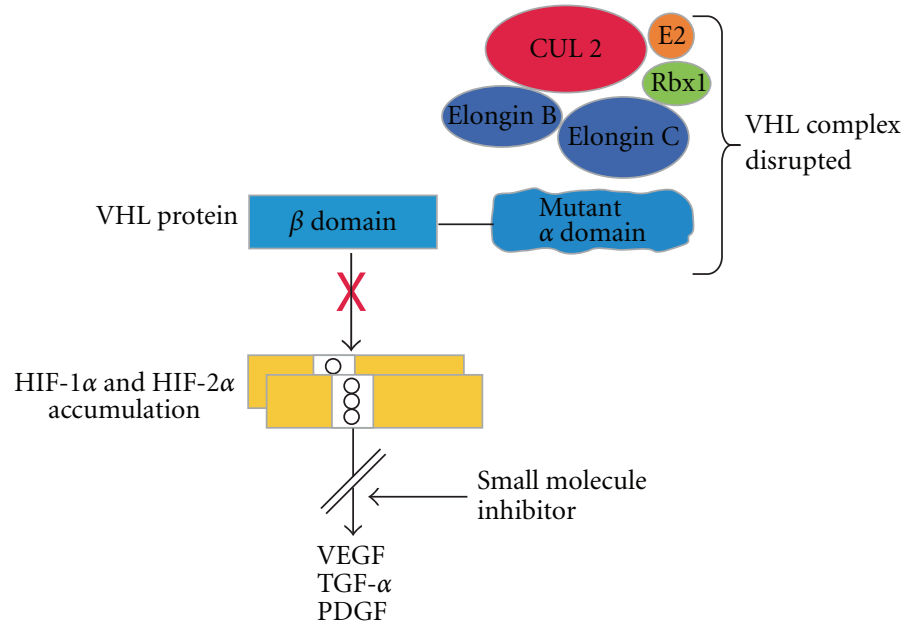

(b)

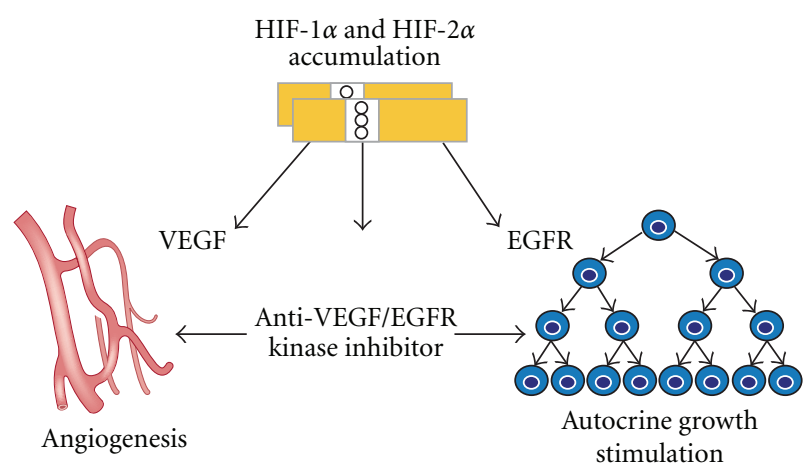

(c)

FIgURE 2: The VHL complex targets HIF- $1 \alpha$ and HIF- $2 \alpha$ for ubiquitin-mediated degradation. In clear cell RCC, an alteration in the VHL gene in the $\alpha$ or $\beta$ domain disrupts HIF degradation. HIF overaccumulates leading to increased transcription of downstream genes. (a) VHL alteration; (b) VHL/HIF pathway molecular targeting; and (c) VHL/HIF downstream molecular targeting. (From Linehan and Zbar [23], with permission.)

RCC are based upon the targeting of the receptors for HIFregulated genes [45]. The agents currently approved by the US Food and Drug Administration to treat metastatic clear cell RCC via the targeting of VHL transcription products include sunitinib, sorafenib, bevacizumab plus interferon- $\alpha$, pazopanib, temsirolimus, and everolimus [19]. These agents form the foundation for systemic therapy in a disease that has been resilient in the face of cytotoxic chemotherapy and radiotherapy $[6,7,21]$. Despite the great progress in the arena of targeted therapy, the bulk of the work has been in clear cell histology, and treatment for other histologic subtypes is presently less well established [22].

\section{Hereditary Papillary Renal Carcinoma}

Hereditary papillary renal carcinoma (HPRC) is an inherited renal cancer syndrome in which affected individuals are at risk of developing multifocal bilateral type 1 papillary renal carcinoma. It follows an autosomal dominant inheritance pattern with very high penetrance, meaning that there is a high likelihood of a person developing papillary RCC by age 80 [46]. Affected individuals are generally at risk of developing tumors in the sixth through eighth decades [47]. The only involved organ in HPRC is the kidney. The tumors are typically well differentiated but are malignant and can 


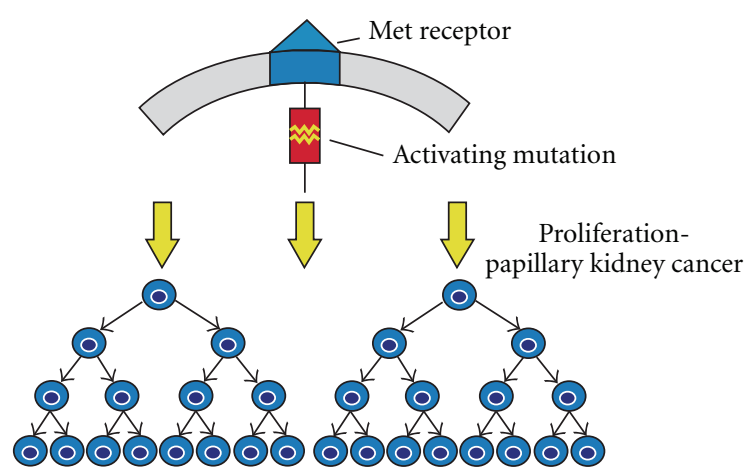

FIGURE 3: Alterations in the intracellular tyrosine kinase domain of the MET proto-oncogene are found in patients with HPRC. These mutations result in the activation of the MET pathway. (From Linehan et al. [10], with permission.)

metastasize. Initial descriptions of the disease describe it as "late onset", occurring in the later decades of life [46, 48]. However, within the last decade, an early onset form of HPRC has been identified [49]. Renal tumors in these patients are often diagnosed incidentally [50].

Computed tomography (CT) and magnetic resonance imaging (MRI) are the imaging modalities of choice when evaluating patients with HPRC as they demonstrate greater sensitivity when compared to renal ultrasound [51]. However, these lesions are typically small and hypovascular with poor enhancement on CT imaging. HPRC lesions can easily be mistaken for renal cysts, and a high index of suspicion is needed. In these cases, ultrasound is a useful adjunct to differentiate cystic from solid lesions, although the solid lesions may be isoechoic to normal renal parenchyma.

HPRC-affected families were evaluated and found to be devoid of abnormalities on chromosome 3 . However, within the first few years of the identification of the syndrome, research yielded the gene responsible for HPRC on chromosome $7 \mathrm{q} 31[46,48]$. The germline alteration in HPRC activates a proto-oncogene. The missense mutations in the tyrosine kinase domain of the MET proto-oncogene at 7q31 are responsible for the constitutive activation of the MET protein. The MET transmembrane protein is located at a hepatocyte growth factor receptor site, and a tyrosine kinase domain is located intracellularly [52]. Hepatocyte growth factor activates MET tyrosine phosphorylation which in turn induces proliferation and differentiation of epithelial and endothelial cells, cell branching, and invasion $[13,53]$ (Figure 3). MET alterations in somatic cells have been identified in a division of patients with sporadic papillary type 1 renal cancer [54]. Changes in the MET gene involve ligandindependent activation of the intracytoplasmic tyrosine kinase domain leading to activation of the hepatocyte growth factor (HGF)/MET pathway resulting in tumor formation $[55,56]$. HPRC families retain germline changes in the MET gene with nonrandom duplication of chromosome 7 with the altered MET allele [57].

Molecular targeting aimed to inhibit HGF, and the subsequent downstream pathways could be a potential therapy of papillary type 1 RCC in patients with HPRC [12].
For example, foretinib is an oral tyrosine kinase receptor inhibitor that targets c-MET and VEGFR2 that has been studied in a phase II multicenter trial [58].

\section{Hereditary Leiomyomatosis and Renal Cell Cancer}

Hereditary leiomyomatosis and renal cell cancer (HLRCC) is a hereditary renal cancer syndrome that was initially reported in 2001 by Launonen et al. [60]. Individuals affected with this syndrome are at risk of developing papillary type 2 renal tumors as well as cutaneous and uterine leiomyomas. These aggressive renal lesions can be mistaken for collecting duct RCC tumors [61]. Although papillary type 2 lesions can occur in a sporadic fashion, those associated with HLRCC tend to occur as unilateral solitary lesions that are very aggressive, prone to metastasis, and lethal if afforded the opportunity to progress $[62,63]$. The gene responsible for HLRCC was identified by Tomlinson et al. on chromosome $1(1 \mathrm{q} 42-44)$ and is known as fumarate hydratase $(F H)$. This gene functions as a tumor suppressor, and both alleles are inactivated in tumor tissue [64]. The FH gene is inherited in an autosomal dominant fashion with high penetrance.

Fumarate hydratase is a critical enzyme in aerobic metabolism. Its role in the Krebs cycle is the conversion of fumarate to malate. Alteration to FH upregulates HIF and creates a pseudohypoxic environment that is similarly seen in VHL. When FH is inactivated, fumarate levels build up and competitively inhibit HIF prolyl hydroxylase (HPH). HPH is a key enzymatic regulator of intracellular HIF levels [65]. When HPH is inactivated, HIF levels rise and transcription of the downstream genes occurs (Figure 4). There is presently no known sporadic counterpart to HLRCC renal malignancy and no evidence to support a relationship between the FH mutation and tumorigenesis in nonfamilial cancers. However, in $93 \%$ of HLRCC families (52/56), germline alterations were identified in the $F H$ gene [66].

Potential areas of systematic therapy for HLRCC will likely be designed to prevent increased HIF levels or target the transcription products of VHL-independent HIF accumulation, such as VEGF and TGF- $\alpha$ /EGFR. One attempt to block the downstream affects of $F H$ inactivation is through the use of erlotinib, an oral EGFR tyrosine kinase inhibitor (TKI). A multicenter phase II trial of this agent in patients with locally advanced and metastatic papillary RCC reported an overall RECIST response rate of $11 \%$ with an additional 24 patients (53\%) experiencing stable disease [67].

Combination therapy with an mTOR inhibitor or VEGF pathway antagonist may potentiate the single agent activity of erlotinib. A phase II trial of erlotinib (EGFR TKI) in combination with bevacizumab (monoclonal antibody against VEGF) is currently underway and is one of the trials designed to evaluate this strategy [68].

\section{Birt-Hogg-Dubé}

Birt-Hogg-Dubé (BHD) is a hereditary renal cancer syndrome that is associated with chromophobe renal tumors. The inheritance pattern is autosomal dominant, and affected 

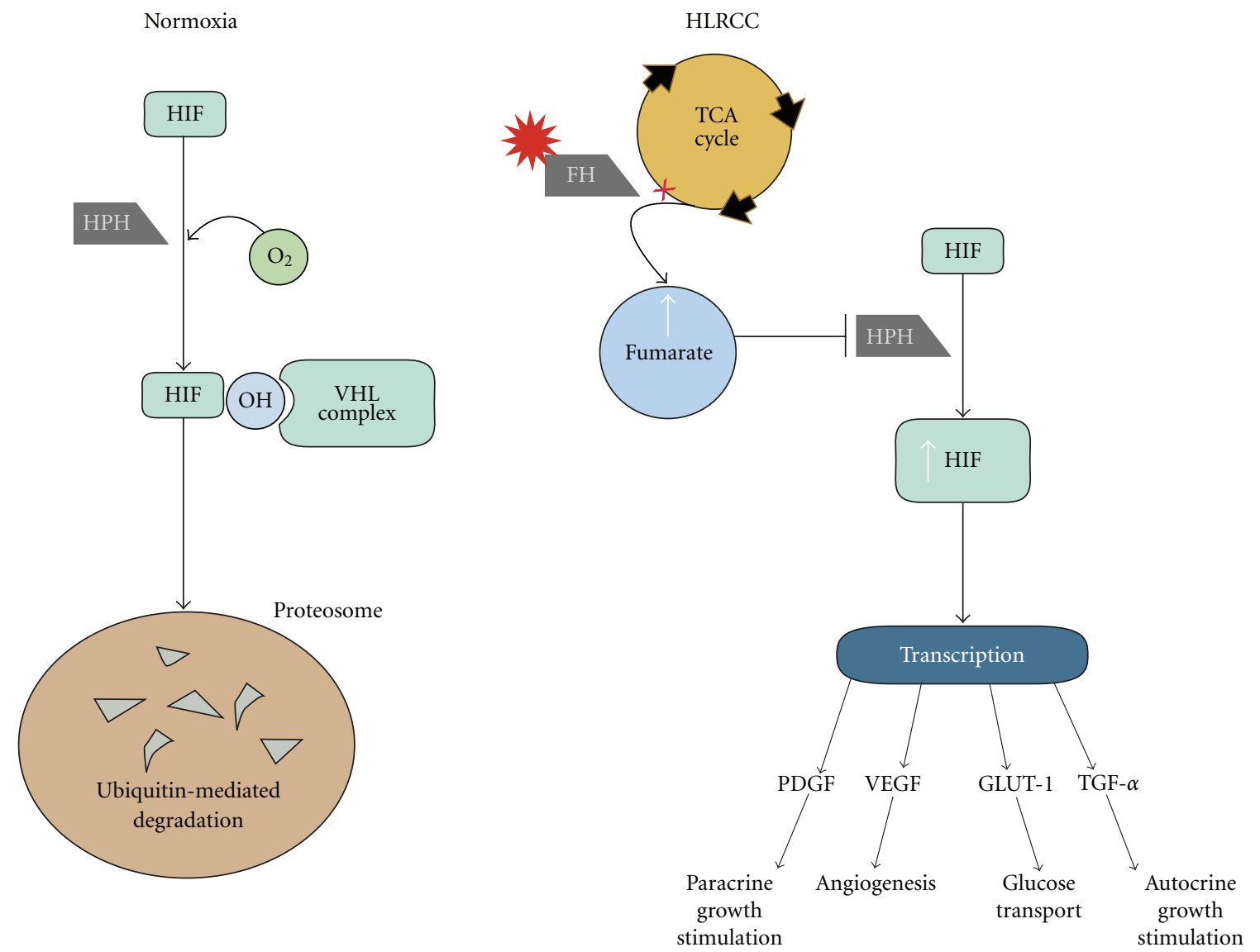

FIGURE 4: In a normoxic environment, HIF is hydroxylated by HPH allowing the VHL complex to initiate ubiquitin-mediated breakdown in the proteosome. In HLRCC, FH alteration results in a buildup of fumarate. Fumarate competitively inhibits HPH allowing a rise in HIF levels and subsequent transcription of downstream genes. (From Pfaffenroth and Linehan [59], with permission.)

individuals develop cutaneous fibrofolliculomas, pulmonary cysts, spontaneous pneumothoraces, and renal tumors [70]. In identified genetic carriers, renal tumors were observed in $14-34 \%$, spontaneous pneumothoracies in $23 \%$, and pulmonary cysts in $83 \%$ [14]. The majority of the renal tumors are of chromophobe histology (33\%), hybrid tumors $(50 \%)$, and oncocytomas (5\%). Multifocal oncocytosis is seen in the surrounding renal parenchyma in $50 \%$ of the affected individuals. In addition, clear cell RCC is seen in patients with BHD [71].

The BHD gene, folliculin (FLCN), was localized to chromosome 17 and was subsequently identified at $17 \mathrm{p} 11.2$ $[72,73] . F L C N$ is altered as a result of insertions, deletions, or nonsense mutations [74]. FLCN deficiency activates the mammalian target of rapamycin (mTOR) pathway [75]. The FLCN gene has the traits of a tumor suppressor and requires two mutations with the second hit inactivating the gene [76].

FLCN forms a complex with folliculin-interacting proteins (FNIP1 and FNIP2). These components intern bind to AMP-activated protein kinase (AMPK). AMPK acts to sense cellular energy and assists in the regulation of the mTOR activity level [75, 77]. In tumors that are noted to have FLCN alterations in both alleles, mTOR activation (mTORC1 and mTORC2) has been observed [69]. Rapamycin inhibits the mTOR pathway and has been noted to prolong survival and reduce renal manifestations of BHD in FLCN knockout mice [78]. This represents a potential therapeutic role for mTOR inhibitors in patients affected by BHD-related renal tumors. At present, the role of mTOR pathways in sporadic chromophobe tumors is under investigation (Figure 5).

\section{Surgical Management}

Patients with FRC are likely to develop multifocal, bilateral, and recurrent renal tumors. In managing these patients, two goals are paramount: prevention of metastatic disease and preservation of renal function. At the National Cancer Institute, the first goal has been achieved largely through diligent surveillance serial cross-sectional imaging and observation until the dominant lesion achieves a size of $3 \mathrm{~cm}$ [79]. When a lesion becomes $3 \mathrm{~cm}$, surgical intervention is recommended. In patients adhering to this " $3 \mathrm{~cm}$ rule", none developed metastatic disease with more than 10 years followup [80]. It should be noted, however, that the $3 \mathrm{~cm}$ rule was initially developed in the VHL population and later expanded to include HPRC and BHD patients. Patients with HLRCC and any evidence of solid tumor are offered surgical extirpation given the highly aggressive nature of their disease. Active surveillance is not recommended for HLRCC patients with renal tumors. The second goal of renal preservation has 


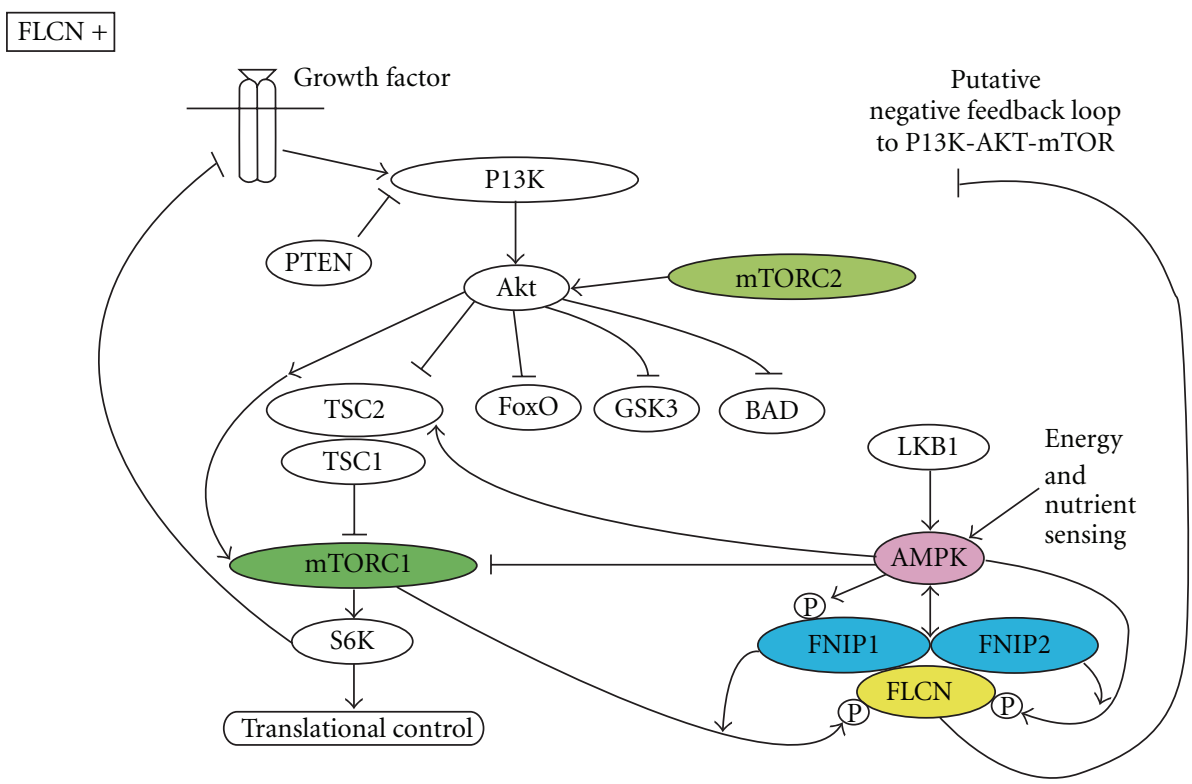

(a)

\section{FLCN -}

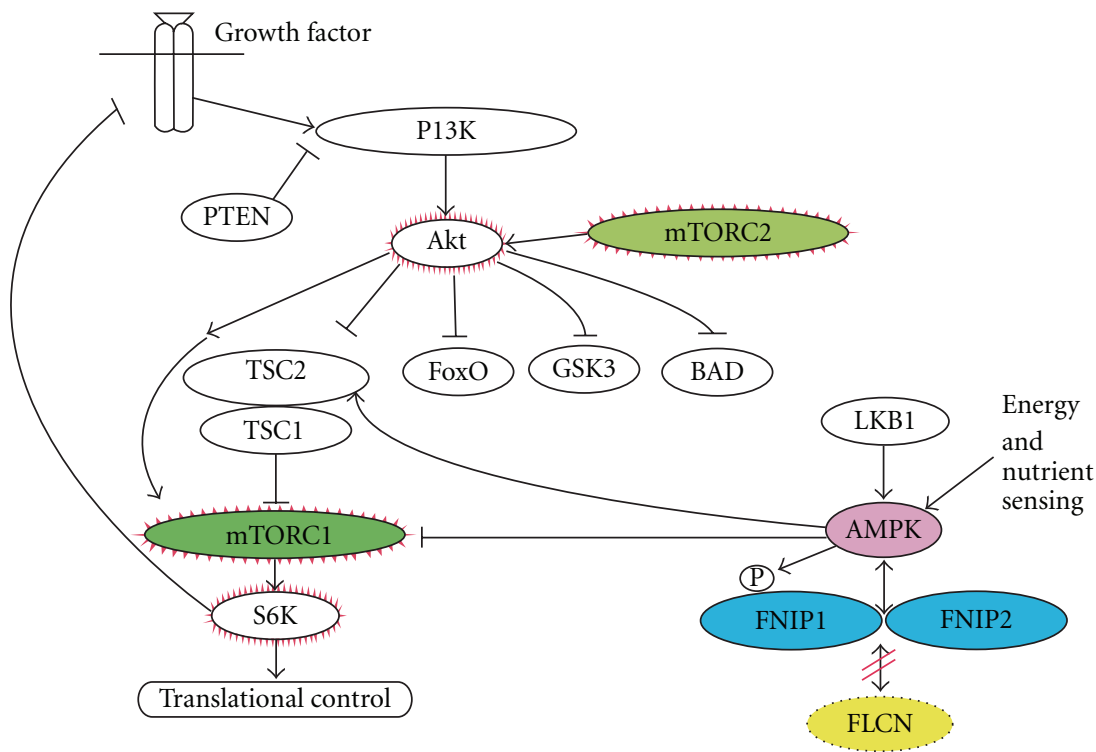

(b)

FIGURE 5: FLCN pathway. (a) FLCN is the gene associated with BHD. Normal FCLN protein complexes with FNIP1, FNIP2, and AMPK. This complex is phosphorylated by a rapamycin-sensitive kinase (mTORC1). (b) When FLCN is altered, it fails to complex and allows activation of AKT, mTORC1, and mTORC2. (From Hasumi et al. [69], with permission.)

been achieved with a committed approach to nephronsparing surgery (NSS) using open, laparoscopic, and robotic approaches [81-83].

The development of locally recurrent renal tumors is rare in sporadic disease but more common in patients with FRC, although it is difficult to distinguish recurrent disease from adjacent de novo tumor in the majority of cases. Disease recurrence in the ipsilateral renal unit has been described at the same site or elsewhere in the kidney after both partial nephrectomy and ablative therapy (cryoablation or radio frequency ablation) [84-86]. This scenario presents a complicated management dilemma, and this particular situation is occurring with greater frequency as a result of the increased use of nephron sparing surgery [82]. In the setting of local recurrence, management options include observation, initial or repeat ablation, repeat or salvage partial nephrectomy, radical nephrectomy, or systemic therapy. Each management option presents a unique array of risks and benefits. The majority of renal units can be salvaged in the face of disease recurrence. However, it comes at the cost of increased perioperative complication rates [82]. 
Reoperation for locally recurrent disease is often associated with a difficult dissection due to disruption of normal anatomic tissue planes as well as perinephric scarring. Complication rates increase with the number and complexity of repeated interventions on the ipsilateral kidney. Greater operative times, blood loss, and perioperative complications are typically observed [87]. The overall major complication rate approaches $20 \%$ with repeat partial nephrectomy [88], whereas complication rates in surgically naïve patients range from $11 \%$ to $13 \%$ [ 89,90$]$. The most common complication among reoperative patients is urinary leak. However, this was noted to resolve in all patients [88]. Other complications include bowel injury, renovascular injury, and, rarely, loss of a renal unit or death. Although the risks associated with repeated surgical intervention on the same renal unit are significant, they are offset by the benefits of avoiding the morbidity and mortality associated with renal replacement therapy. While the treatment algorithm offers many branch points, the complexity and increased risk associated with these procedures demand referral to an experienced surgeon at a medical center that can provide comprehensive care.

In cases of metastatic disease, surgical treatment options alone are typically inadequate. Systemic therapies that target VEGF, VEGFR, and mTOR are commonly used. While the agents in these drug classes have been shown to improve progression-free survival and overall survival, durable complete responses are uncommon. For patients with clear cell RCC and a good performance status, treatment with IL-2 is often considered as it is the only systemic therapy shown to provide the opportunity for durable complete responses [91]. Given the improving yet limited efficacy of systemic therapy for RCC, aggressive surgical extirpation, including lymphadenectomy and metastectomy in select patients, should remain the treatment of choice whenever technically feasible $[92,93]$.

\section{Conclusions}

FRC is a heterogeneous disease and represents a spectrum of cancer gene pathways. Having a high suspicion for the presence of FRC allows for the appropriate counseling, screening, and surveillance of the patient and other potentially affected kindred. The complexity of these pathways requires unique therapeutic management strategies for each cancer syndrome. Understanding these pathways has led to improved management of affected patients. Using a strategy aimed at renal preservation and prevention of systemic disease, the care of FRC patients and families has been optimized. However, it is clear that no single strategy offers a comprehensive solution. The continuation of translational research, diligent surveillance programs, NSS, and the management of systemic disease with immunotherapy and novel-targeted therapies appears to be the most efficacious contemporary strategy.

\section{Acknowledgment}

This paper was supported by the Intramural Research Program of the NIH, National Cancer Institute, Center for Cancer Research.

\section{Disclosure}

The views expressed in this paper are those of the authors and do not necessarily reflect the official policy or position of the Department of the Navy, Army, Department of Defense, nor the US Government.

The authors certify that all individuals who qualify as authors have been listed; that each has participated in the conception and design of this work, the analysis of data (when applicable), the writing of the document, and the approval of the submission of this version; that the document represents valid work; that if we used information derived from another source, they obtained all necessary approvals to use it and made the appropriate acknowledgments in the document; that each takes public responsibility for it. Nothing in the presentation implies any Federal/DOD/ DON/DOA endorsement.

\section{References}

[1] A. Jemal, F. Bray, M. M. Center, J. Ferlay, E. Ward, and D. Forman, "Global cancer statistics," CA: Cancer Journal for Clinicians, vol. 61, no. 2, pp. 69-90, 2011.

[2] A. Jemal, R. Siegel, J. Xu, and E. Ward, "Cancer statistics, 2010," CA: Cancer Journal for Clinicians, vol. 60, no. 5, pp. 277300, 2010.

[3] S. Altekruse, C. Kosary, M. Krapcho et al., "Seer cancer statistics review, 1975-2007, National Cancer Institute," 2009, http://seer.cancer.gov/statfacts/html/kidrp.html\#risk.

[4] J. M. Hollingsworth, D. C. Miller, S. Daignault, and B. K. Hollenbeck, "Rising incidence of small renal masses: a need to reassess treatment effect," Journal of the National Cancer Institute, vol. 98, no. 18, pp. 1331-1334, 2006.

[5] W. H. Chow, S. S. Devesa, J. L. Warren, and J. F. Fraumeni, "Rising incidence of renal cell cancer in the United States," Journal of the American Medical Association, vol. 281, no. 17, pp. 1628-1631, 1999.

[6] A. Yagoda, D. Petrylak, and S. Thompson, "Cytotoxic chemotherapy for advanced renal cell carcinoma," Urologic Clinics of North America, vol. 20, no. 2, pp. 303-321, 1993.

[7] E. C. Nelson, C. P. Evans, and P. N. Lara, "Renal cell carcinoma: current status and emerging therapies," Cancer Treatment Reviews, vol. 33, no. 3, pp. 299-313, 2007.

[8] K. Uchida, N. Miyao, N. Masumori et al., "Recurrence of renal cell carcinoma more than 5 years after nephrectomy," International Journal of Urology, vol. 9, no. 1, pp. 19-23, 2002.

[9] G. Kovacs, M. Akhtar, B. J. Beckwith et al., "The Heidelberg classification of renal cell tumours," The Journal of pathology, vol. 183, no. 2, pp. 131-133, 1997.

[10] W. M. Linehan, M. M. Walther, and B. Zbar, "The genetic basis of cancer of the kidney," Journal of Urology, vol. 170, no. 6, pp. 2163-2172, 2003.

[11] G. Kovacs, A. Emanuel, H. P. H. Neumann, and H. F. Kung, "Cytogenetics of renal cell carcinomas associated with von Hippel-Lindau disease," Genes Chromosomes and Cancer, vol. 3, no. 4, pp. 256-262, 1991. 
[12] W. M. Linehan, J. Vasselli, R. Srinivasan et al., "Genetic basis of cancer of the kidney: disease-specific approaches to therapy," Clinical Cancer Research, vol. 10, no. 18, part 2, pp. 6282S6289S, 2004.

[13] I. Rosner, G. Bratslavsky, P. A. Pinto, and W. M. Linehan, "The clinical implications of the genetics of renal cell carcinoma," Urologic Oncology, vol. 27, no. 2, pp. 131-136, 2009.

[14] J. A. Coleman and P. Russo, "Hereditary and familial kidney cancer," Current Opinion in Urology, vol. 19, no. 5, pp. 478485, 2009.

[15] B. I. Rini, S. C. Campbell, and W. K. Rathmell, "Renal cell carcinoma," Current Opinion in Oncology, vol. 18, no. 3, pp. 289-296, 2006.

[16] B. Zbar, G. Glenn, M. Merino et al., "Familial renal carcinoma: clinical evaluation, clinical subtypes and risk of renal carcinoma development," Journal of Urology, vol. 177, no. 2, pp. 461-465, 2007.

[17] M. E. Robson, C. D. Storm, J. Weitzel, D. S. Wollins, and K. Offit, "American Society of Clinical Oncology Policy Statement update: genetic and genomic testing for cancer susceptibility," Journal of Clinical Oncology, vol. 28, no. 5, pp. 893-901, 2010.

[18] W. M. Linehan, G. Bratslavsky, P. A. Pinto et al., "Molecular diagnosis and therapy of kidney cancer," Annual Review of Medicine, vol. 61, pp. 329-343, 2010.

[19] E. A. Singer, G. N. Gupta, and R. Srinivasan, "Update on targeted therapies for clear cell renal cell carcinoma," Current Opinion in Oncology, vol. 23, no. 3, pp. 283-289, 2011.

[20] G. Di Lorenzo, R. Autorino, and C. N. Sternberg, "Metastatic renal cell carcinoma: recent advances in the targeted therapy era," European Urology, vol. 56, no. 6, pp. 959-971, 2009.

[21] B. I. Rini, "Metastatic renal cell carcinoma: many treatment options, one patient," Journal of Clinical Oncology, vol. 27, no. 19, pp. 3225-3234, 2009.

[22] E. A. Singer, G. Bratslavsky, W. M. Linehan, and R. Srinivasan, "Targeted therapies for non-clear renal cell carcinoma," Targeted Oncology, vol. 5, no. 2, pp. 119-129, 2010.

[23] W. M. Linehan and B. Zbar, "Focus on kidney cancer," Cancer Cell, vol. 6, no. 3, pp. 223-228, 2004.

[24] M. M. Walther, I. A. Lubensky, D. Venzon, B. Zbar, W. M. Linehan, and F. F. Marshall, "Prevalence of microscopic lesions in grossly normal renal parenchyma from patients with Von Hippel-Lindau disease, sporadic renal cell carcinoma and no renal disease: clinical implications," Journal of Urology, vol. 154, no. 6, pp. 2010-2015, 1995.

[25] E. R. Maher, L. Iselius, J. R. W. Yates et al., "Von Hippel-Lindau disease: a genetic study," Journal of Medical Genetics, vol. 28, no. 7, pp. 443-447, 1991.

[26] G. Glenn, P. Choyke, B. Zbar, and W. M. Linehan, "Von hippellindau disease: clinical review and molecular genetics," in Problems in Urologic Surgery: Benign and Malignant Tumors of the Kidney, pp. 312-330, J. B. Lippincott, Philadelphia, Pa, USA, 1990.

[27] K. Tory, H. Brauch, M. Linehan et al., "Specific genetic change in tumors associated with von Hippel-Lindau disease," Journal of the National Cancer Institute, vol. 81, no. 14, pp. 1097-1101, 1989.

[28] S. Hosoe, H. Brauch, F. Latif et al., "Localization of the von Hippel-Lindau disease gene to a small region of chromosome 3," Genomics, vol. 8, no. 4, pp. 634-640, 1990.

[29] F. Latif, K. Tory, J. Gnarra et al., "Identification of the von Hippel-Lindau disease tumor suppressor gene," Science, vol. 260, no. 5112, pp. 1317-1320, 1993.
[30] B. Zbar, H. Brauch, C. Talmadge, and M. Linehau, "Loss of alleles of loci on the short arm of chromosome 3 in renal cell carcinoma," Nature, vol. 327, no. 6124, pp. 721-724, 1987.

[31] C. Stolle, G. Glenn, B. Zbar et al., "Improved detection of germline mutations in the von Hippel-Lindau disease tumor suppressor gene," Human Mutation, vol. 12, no. 6, pp. 417423, 1998.

[32] J. R. Gnarra, K. Tory, Y. Weng et al., "Mutations of the VHL tumour suppressor gene in renal carcinoma," Nature Genetics, vol. 7, no. 1, pp. 85-90, 1994.

[33] R. O. Kai, E. R. Woodward, P. Killick, C. Lim, F. Macdonald, and E. R. Maher, "Genotype-phenotype correlations in von Hippel-Lindau disease," Human Mutation, vol. 28, no. 2, pp. 143-149, 2007.

[34] C. Gallou, D. Chauveau, S. Richard et al., "Genotype-phenotype correlation in von Hippel-Lindau families with renal lesions," Human Mutation, vol. 24, no. 3, pp. 215-224, 2004.

[35] P. H. Hartmut, P. H. Neumann, and B. Zbar, "Renal cysts, renal cancer and von Hippel-Lindau disease," Kidney International, vol. 51, no. 1, pp. 16-26, 1997.

[36] F. Chen, T. Kishida, M. Yao et al., "Germline mutations in the von Hippel-Lindau disease tumor suppressor gene: correlations with phenotype," Human Mutation, vol. 5, no. 1, pp. 66-75, 1995.

[37] J. K. Maranchie, A. Afonso, P. S. Albert et al., "Solid renal tumor severity in von Hippel Lindau disease is related to germline deletion length and location," Human Mutation, vol. 23, no. 1, pp. 40-46, 2004.

[38] D. R. Duan, A. Pause, W. H. Burgess et al., "Inhibition of transcription elongation by the VHL tumor suppressor protein," Science, vol. 269, no. 5229, pp. 1402-1406, 1995.

[39] A. Kibel, O. Iliopoulos, J. A. DeCaprio, and W. G. Kaelin, "Binding of the von Hippel-Lindau tumor suppressor protein to Elongin B and C," Science, vol. 269, no. 5229, pp. 1444-1446, 1995.

[40] A. Pause, S. Lee, R. A. Worrell et al., "The von Hippel-Lindau tumor-suppressor gene product forms a stable complex with human CUL-2, a member of the Cdc53 family of proteins," Proceedings of the National Academy of Sciences of the United States of America, vol. 94, no. 6, pp. 2156-2161, 1997.

[41] J. Brugarolas and W. G. Kaelin, "Dysregulation of HIF and VEGF is a unifying feature of the familial hamartoma syndromes," Cancer Cell, vol. 6, no. 1, pp. 7-10, 2004.

[42] O. Iliopoulos, A. P. Levy, C. Jiang, W. G. Kaelin, and M. A. Goldberg, "Negative regulation of hypoxia-inducible genes by the von Hippel-Lindau protein," Proceedings of the National Academy of Sciences of the United States of America, vol. 93, no. 20, pp. 10595-10599, 1996.

[43] E. A. Singer, G. Bratslavsky, L. Middelton, R. Srinivasan, and W. M. Linehan, "Impact of genetics on the diagnosis and treatment of renal cancer," Current Urology Reports, vol. 12, no. 1, pp. 47-55, 2011.

[44] W. G. Kaelin, "The von Hippel-Lindau tumor suppressor protein and clear cell renal carcinoma," Clinical Cancer Research, vol. 13, no. 2, part 2, pp. 680s-684s, 2007.

[45] W. M. Linehan, "Editorial: Kidney cancer-a unique opportunity for the development of disease specific therapy," Journal of Urology, vol. 168, no. 6, pp. 2411-2412, 2002.

[46] L. Schmidt, K. Junker, G. Weirich et al., "Two North American families with hereditary papillary renal carcinoma and identical novel mutations in the MET proto-oncogene," Cancer Research, vol. 58, no. 8, pp. 1719-1722, 1998. 
[47] B. Zbar, K. Tory, M. Merino et al., "Hereditary papillary renal cell carcinoma," Journal of Urology, vol. 151, no. 3, pp. 561$566,1994$.

[48] L. Schmidt, F.-M. Duh, F. Chen et al., "Germline and somatic mutations in the tyrosine kinase domain of the MET protooncogene in papillary renal carcinomas," Nature Genetics, vol. 16, no. 1, pp. 68-73, 1997.

[49] L. S. Schmidt, M. L. Nickerson, D. Angeloni et al., "Early onset hereditary papillary renal carcinoma: germline missense mutations in the tyrosine kinase domain of the MET protooncogene," Journal of Urology, vol. 172, no. 4, pp. 1256-1261, 2004.

[50] B. Zbar, G. Glenn, I. Lubensky et al., "Hereditary papillary renal cell carcinoma: clinical studies in 10 families," Journal of Urology, vol. 153, no. 3, part 2, pp. 907-912, 1995.

[51] P. L. Choyke, M. M. Walther, G. M. Glenn et al., "Imaging features of hereditary papillary renal cancers," Journal of Computer Assisted Tomography, vol. 21, no. 5, pp. 737-741, 1997.

[52] D. P. Bottaro, J. S. Rubin, D. L. Faletto et al., "Identification of the hepatocyte growth factor receptor as the c-met protooncogene product," Science, vol. 251, no. 4995, pp. 802-804, 1991.

[53] Y. W. Zhang and G. F. Vande Woude, "HGF/SF-Met signaling in the control of branching morphogenesis and invasion," Journal of Cellular Biochemistry, vol. 88, no. 2, pp. 408-417, 2003.

[54] L. Schmidt, K. Junker, N. Nakaigawa et al., "Novel mutations of the MET proto-oncogene in papillary renal carcinomas," Oncogene, vol. 18, no. 14, pp. 2343-2350, 1999.

[55] J. S. Choi, M. K. Kim, J. W. Seo et al., "MET expression in sporadic renal cell carcinomas," Journal of Korean Medical Science, vol. 21, no. 4, pp. 672-677, 2006.

[56] P. G. Dharmawardana, A. Giubellino, and D. P. Bottaro, "Hereditary papillary renal carcinoma type I," Current Molecular Medicine, vol. 4, no. 8, pp. 855-868, 2004.

[57] Z. Zhuang, W. S. Park, S. Pack et al., “Trisomy 7-harbouring non-random duplication of the mutant MET allele in hereditary papillary renal carcinomas," Nature Genetics, vol. 20, no. 1, pp. 66-69, 1998.

[58] R. Srinivasan, W. M. Linehan, U. Vaishampayan et al., "A phase ii study of two dosing regimens of gsk 1363089 (gsk089), a dual met/vegfr2 inhibitor, in patients (pts) with papillary renal carcinoma (prc)," Journal of Clinical Oncology, vol. 27, no. 15S, abstract 5103, 2009.

[59] E. C. Pfaffenroth and W. M. Linehan, "Genetic basis for kidney cancer: opportunity for disease-specific approaches to therapy," Expert Opinion on Biological Therapy, vol. 8, no. 6, pp. 779-790, 2008.

[60] V. Launonen, O. Vierimaa, M. Kiuru et al., "Inherited susceptibility to uterine leiomyomas and renal cell cancer," Proceedings of the National Academy of Sciences of the United States of America, vol. 98, no. 6, pp. 3387-3392, 2001.

[61] M. J. Merino, C. Torres-Cabala, P. Pinto, and W. Marston Linehan, "The morphologic spectrum of kidney tumors in hereditary leiomyomatosis and renal cell carcinoma (HLRCC) syndrome," American Journal of Surgical Pathology, vol. 31, no. 10, pp. 1578-1585, 2007.

[62] R. L. Grubb, M. E. Franks, J. Toro et al., "Hereditary leiomyomatosis and renal cell cancer: a syndrome associated with an aggressive form of inherited renal cancer," Journal of Urology, vol. 177, no. 6, pp. 2074-2080, 2007.

[63] W. M. Linehan, P. A. Pinto, R. Srinivasan et al., "Identification of the genes for kidney cancer: opportunity for disease-specific targeted therapeutics," Clinical Cancer Research, vol. 13, no. 2, part 2, pp. 671s-679s, 2007.

[64] I. P. M. Tomlinson, N. A. Alam, A. J. Rowan et al., "Germline mutations in $\mathrm{FH}$ predispose to dominantly inherited uterine fibroids, skin leiomyomata and papillary renal cell cancer the multiple leiomyoma consortium," Nature Genetics, vol. 30, no. 4, pp. 406-410, 2002.

[65] J. S. Isaacs, J. J. Yun, D. R. Mole et al., "HIF overexpression correlates with biallelic loss of fumarate hydratase in renal cancer: novel role of fumarate in regulation of HIF stability," Cancer Cell, vol. 8, no. 2, pp. 143-153, 2005.

[66] J. R. Toro, M. L. Nickerson, M. H. Wei et al., "Mutations in the fumarate hydratase gene cause hereditary leiomyomatosis and renal cell cancer in families in North America," American Journal of Human Genetics, vol. 73, no. 1, pp. 95-106, 2003.

[67] M. S. Gordon, M. Hussey, R. B. Nagle et al., "Phase II study of erlotinib in patients with locally advanced or metastatic papillary histology renal cell cancer: SWOG S0317," Journal of Clinical Oncology, vol. 27, no. 34, pp. 5788-5793, 2009.

[68] NIH, "A phase ii study of bevacizumab and erlotinib in subjects with advanced hereditary leiomyomatosis and renal cell cancer (hlrcc) or sporadic papillary renal cell cancer," 2011, http://clinicaltrials.gov/ct2/show/NCT01130519?term= bevacizumab+and+erlotinib\&rank $=2$.

[69] Y. Hasumi, M. Baba, R. Ajima et al., "Homozygous loss of BHD causes early embryonic lethality and kidney tumor development with activation of mTORC1 and mTORC2," Proceedings of the National Academy of Sciences of the United States of America, vol. 106, no. 44, pp. 18722-18727, 2009.

[70] B. Zbar, W. G. Alvord, G. Glenn et al., "Risk of renal and colonic neoplasms and spontaneous pneumothorax pneurnothorax in the Birt-Hogg-Dubé syndrome," Cancer Epidemiology Biomarkers and Prevention, vol. 11, no. 4, pp. 393-400, 2002.

[71] C. P. Pavlovich, M. M. Walther, R. A. Eyler et al., "Renal tumors in the Birt-Hogg-Dubé syndrome," American Journal of Surgical Pathology, vol. 26, no. 12, pp. 1542-1552, 2002.

[72] L. S. Schmidt, M. B. Warren, M. L. Nickerson et al., "BirtHogg-Dubé syndrome, a genodermatosis associated with spontaneous pneumothorax and kidney neoplasia, maps to chromosome 17p11.2," American Journal of Human Genetics, vol. 69, no. 4, pp. 876-882, 2001.

[73] M. L. Nickerson, M. B. Warren, J. R. Toro et al., "Mutations in a novel gene lead to kidney tumors, lung wall defects, and benign tumors of the hair follicle in patients with the BirtHogg-Dubé syndrome," Cancer Cell, vol. 2, no. 2, pp. 157-164, 2002.

[74] L. S. Schmidt, M. L. Nickerson, M. B. Warren et al., "Germline BHD-mutation spectrum and phenotype analysis of a large cohort of families with Birt-Hogg-Dubé syndrome," American Journal of Human Genetics, vol. 76, no. 6, pp. 1023-1033, 2005.

[75] M. Baba, S. B. Hong, N. Sharma et al., "Folliculin encoded by the BHD gene interacts with a binding protein, FNIP1, and AMPK, and is involved in AMPK and mTOR signaling," Proceedings of the National Academy of Sciences of the United States of America, vol. 103, no. 42, pp. 15552-15557, 2006.

[76] C. D. Vocke, Y. Yang, C. P. Pavlovich et al., "High frequency of somatic frameshift BHD gene mutations in Birt-HoggDubé-associated renal tumors," Journal of the National Cancer Institute, vol. 97, no. 12, pp. 931-935, 2005.

[77] H. Hasumi, M. Baba, S. B. Hong et al., "Identification and characterization of a novel folliculin-interacting protein FNIP2," Gene, vol. 415, no. 1-2, pp. 60-67, 2008. 
[78] M. Baba, M. Furihata, S. B. Hong et al., "Kidney-targeted BirtHogg-Dubé gene inactivation in a mouse model: Erk1/2 and Akt-mTOR activation, cell hyperproliferation, and polycystic kidneys," Journal of the National Cancer Institute, vol. 100, no. 2, pp. 140-154, 2008.

[79] M. M. Walther, P. L. Choyke, G. Glenn et al., "Renal cancer in families with hereditary renal cancer: prospective analysis of a tumor size threshold for renal parenchymal sparing surgery," Journal of Urology, vol. 161, no. 5, pp. 1475-1479, 1999.

[80] J. C. Herring, E. G. Enquist, A. Chernoff, W. M. Linehan, P. L. Choyke, and M. M. Walther, "Parenchymal sparing surgery in patients with hereditary renal cell carcinoma: 10-year experience," Journal of Urology, vol. 165, no. 3, pp. 777-781, 2001.

[81] R. Boris, M. Proano, W. M. Linehan, P. A. Pinto, and G. Bratslavsky, "Initial experience with robot assisted partial nephrectomy for multiple renal masses," Journal of Urology, vol. 182, no. 4, pp. 1280-1286, 2009.

[82] E. A. Singer and G. Bratslavsky, "Management of locally recurrent kidney cancer," Current Urology Reports, vol. 11, no. 1, pp. 15-21, 2010.

[83] M. M. Walther, P. L. Choyke, G. Weiss et al., "Parenchymal sparing surgery in patients with hereditary renal cell carcinoma," Journal of Urology, vol. 153, no. 3, part 2, pp. 913-916, 1995.

[84] A. Belldegrun, K. H. Tsui, J. B. DeKernion, and R. B. Smith, "Efficacy of nephron-sparing surgery for renal cell carcinoma: analysis based on the new 1997 tumor-node-metastasis staging system," Journal of Clinical Oncology, vol. 17, no. 9, pp. 28682875, 1999.

[85] K. S. Hafez, A. F. Fergany, and A. C. Novick, "Nephron sparing surgery for localized renal cell carcinoma: impact of tumor size on patient survival, tumor recurrence and TNM staging," Journal of Urology, vol. 162, no. 6, pp. 1930-1933, 1999.

[86] D. A. Kunkle, B. L. Egleston, and R. G. Uzzo, "Excise, ablate or observe: the small renal mass dilemma-a meta-analysis and review," Journal of Urology, vol. 179, no. 4, pp. 1227-1234, 2008.

[87] N. W. Liu, K. Khurana, S. Sudarshan, P. A. Pinto, W. M. Linehan, and G. Bratslavsky, "Repeat partial nephrectomy on the solitary kidney: surgical, functional and oncological outcomes," Journal of Urology, vol. 183, no. 5, pp. 1719-1724, 2010.

[88] A. Johnson, S. Sudarshan, J. Liu, W. M. Linehan, P. A. Pinto, and G. Bratslavsky, "Feasibility and outcomes of repeat partial nephrectomy," Journal of Urology, vol. 180, no. 1, pp. 89-93, 2008.

[89] G. Pasticier, M. O. Timsit, L. Badet et al., "Nephron-sparing surgery for renal cell carcinoma: detailed analysis of complications over a 15-year period," European Urology, vol. 49, no. 3, pp. 485-490, 2006.

[90] E. R. Ray, B. W. Turney, R. Singh, A. Chandra, D. W. Cranston, and T. S. O'Brien, "Open partial nephrectomy: outcomes from two UK centres," BJU International, vol. 97, no. 6, pp. 12111215, 2006.

[91] J. C. Yang, R. M. Sherry, S. M. Steinberg et al., "Randomized study of high-dose and low-dose interleukin-2 in patients with metastatic renal cancer," Journal of Clinical Oncology, vol. 21, no. 16, pp. 3127-3132, 2003.

[92] A. L. Alt, S. A. Boorjian, C. M. Lohse, B. A. Costello, B. C. Leibovich, and M. L. Blute, "Survival after complete surgical resection of multiple metastases from renal cell carcinoma," Cancer, vol. 117, no. 13, pp. 2873-2882, 2011.
[93] P. L. Crispen, R. H. Breau, C. Allmer et al., "Lymph node dissection at the time of radical nephrectomy for high-risk clear cell renal cell carcinoma: indications and recommendations for surgical templates," European Urology, vol. 59, no. 1, pp. $18-23,2011$. 


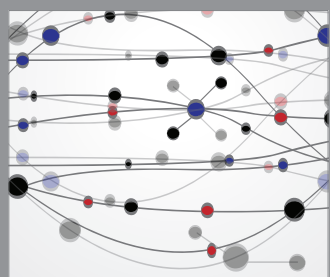

The Scientific World Journal
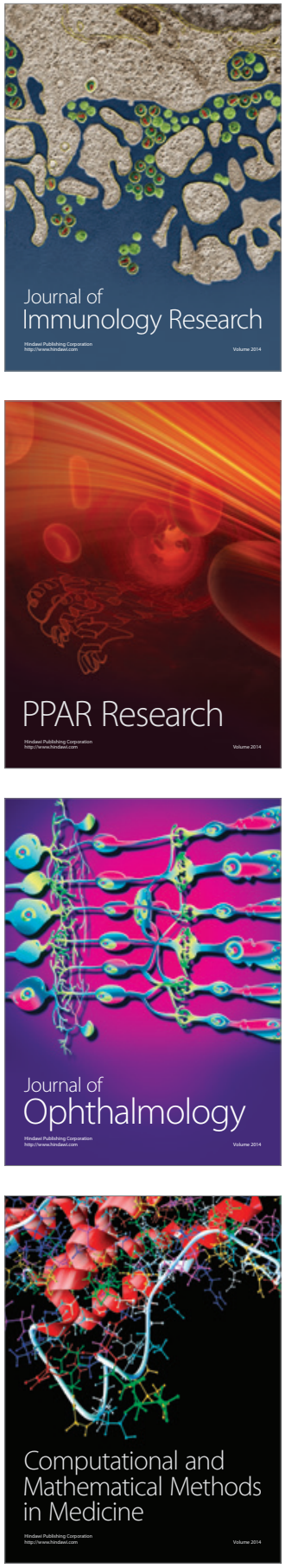

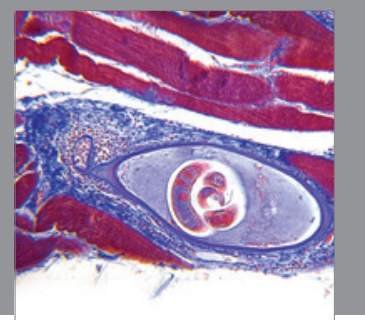

Gastroenterology

Research and Practice
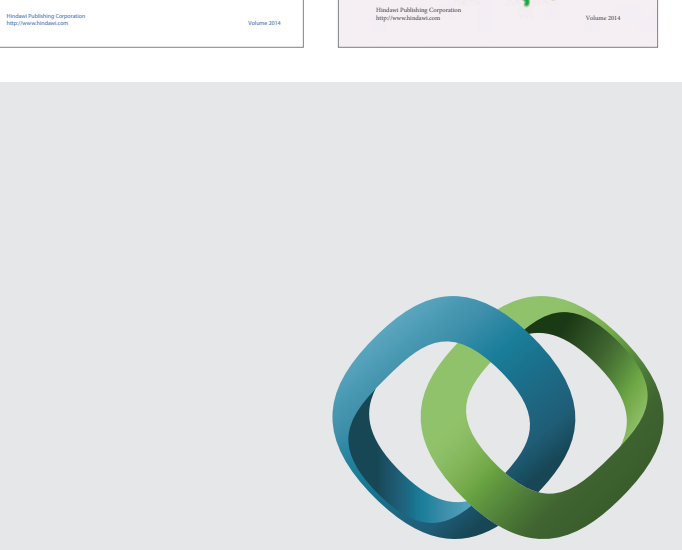

\section{Hindawi}

Submit your manuscripts at

http://www.hindawi.com
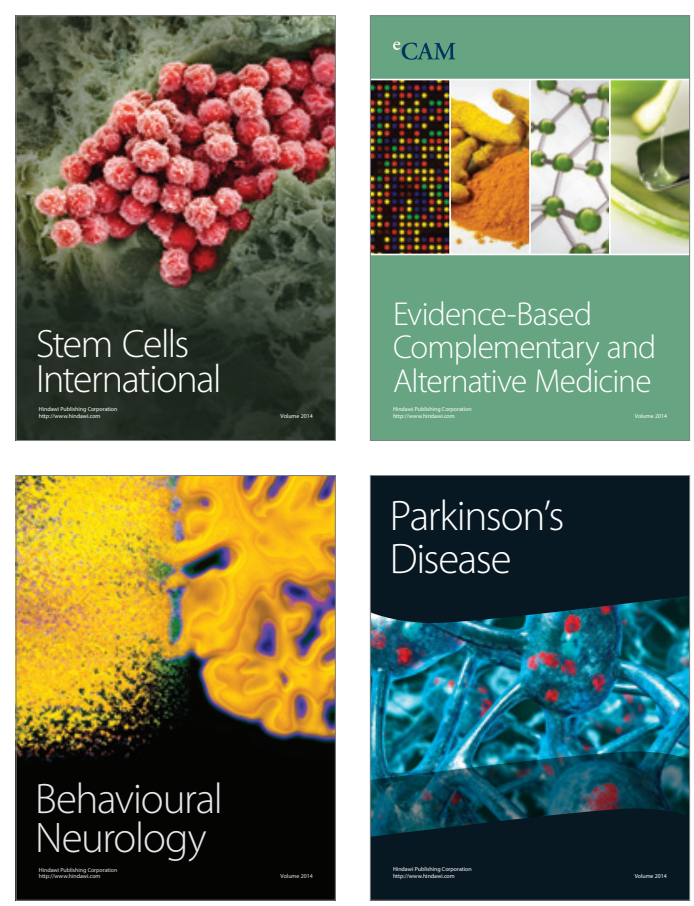

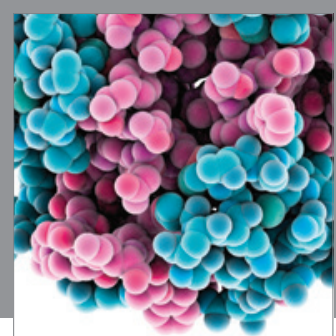

Journal of
Diabetes Research

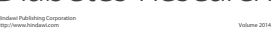

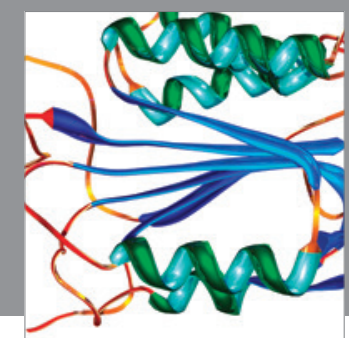

Disease Markers
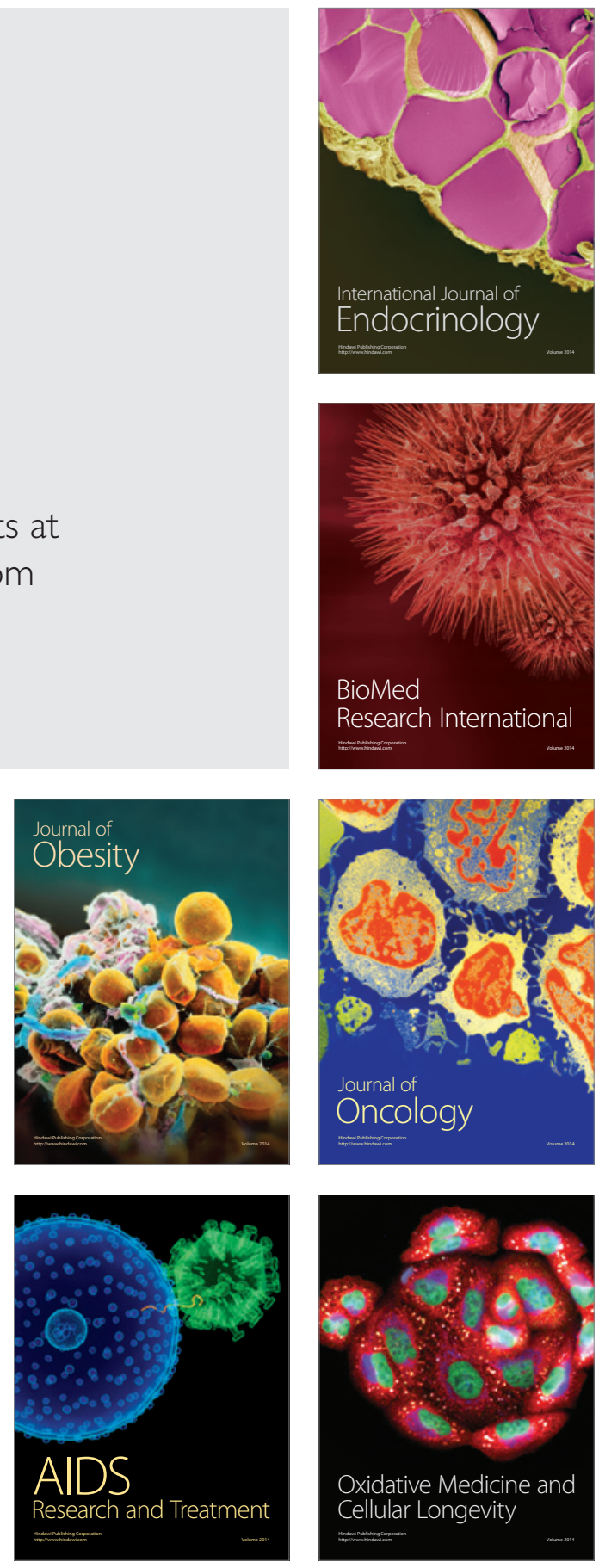